\title{
Effect of simulated soil erosion and organic manures on soil properties
}

\author{
Lovilhunuo, Manoj Dutta, Rizongba Kichu and Sewak Ram
}

MEMBERS OF RESEARCH FORUM:

Corresponding author :

Manoj Dutta, Department of Soil and Water Conservation, School of

Agricultural Sciences and Rural

Development, Nagaland University, Medziphema Campus, Medziphema (Nagaland) India

Email: manojdutta1997@yahoo.com

Co-authors :

Lovilhunuo, Rizongba Kichu and Sewak Ram, Department of Soil and Water Conservation, School of Agricultural Sciences and Rural Development, Nagaland University, Medziphema Campus, Medziphema (Nagaland) India

Email: avinokehie20@gmail.com; rizong09@gmail.com; sewaksasrd@gmail.com
Received : 20.02.2020; Revised : 06.05.2020; Accepted : 23.05.2020

\section{Summary}

A field experiment was carried out to evaluate the effects of simulated erosion and the impact of organic manures on soil physico-chemical properties. The experiment was conducted in split- plot design which comprised of three levels of simulated erosion depths viz., 0, 5 and 10 $\mathrm{cm}$ used as the main plot. Organic manures (vermicompost, poultry manure and pig manure @ 5,3 and $3 \mathrm{t}^{-1}$ ha, respectively) were used as the sub plot treatment. There was a significant effect on the physico-chemical properties of soil due to erosion. The available nitrogen decreased at a rate of 2.86 and 7.81 per cent; available $P$ decreased at a rate of 9.09 and 17.18 per cent; available K decreased at a rate of 9.52 and 15.12 per cent; organic carbon decreased at a rate of 0.07 and 0.15 per cent; CEC decreased at a rate of 2.81 and 5.48 per cent; water holding capacity decreased at the rate of 4.07 and 7.29 per cent while bulk density increased at a rate of 3.49 and 9.30 per cent and soil $\mathrm{pH}$ decreased at a rate of 4.12 and 7.20 per cent, respectively with subsequent removal of 5 and $10 \mathrm{~cm}$ topsoil as compared to control. Addition of organic manures improved the soil properties but could not entirely compensate the loss due to simulated erosion.

Key words : Simulated erosion, Organic manures, Soil physico-chemical properties

How to cite this article : Lovilhunuo, Dutta, Manoj, Kichu, Rizongba and Ram, Sewak (2020). Effect of simulated soil erosion and organic manures on soil properties. Asian J. Soil Sci., 15 (1) : 34-40 : DOI : 10.15740/HAS/AJSS/15.1/34-40. Copyright@ 2020: Hind Agri-Horticultural Society. 